\title{
Thyroid Hemiagenesis Is a Rare Variant of Thyroid Dysgenesis with a Familial Component but without Pax8 Mutations in a Cohort of 22 Cases
}

\author{
MIREILLE CASTANET, LAURENCE LEENHARDT, JULIANE LÉGER, AURORE SIMON-CARRÉ, \\ STANISLAS LYONNET, ANNA PELET, PAUL CZERNICHOW, AND MICHEL POLAK \\ INSERM U457 [M.C., J.L., P.C., M.P.], Robert Debré Teaching Hospital, Paris 75019, France, \\ Department of Nuclear Medicine [L.L.], Pitié-Salpêtrière Teaching Hospital, Paris 75005, France, \\ INSERM U393 [S.L., A.P.], Paediatric Endocrinology Unit [M.P.], EMI 0363 [A.S-C., M.P.], Necker \\ Enfants-Malades Teaching Hospital, Paris 75015, France
}

\begin{abstract}
Thyroid hemiagenesis is a rare form of thyroid dysgenesis of which some familial cases have been reported, including one associated with a heterozygous mutation in the Pax8 gene. However, the physiopathology remains not well known. The objectives of this study were 1) to describe the clinical features, 2) to look for familial clustering, and 3) to search for $\operatorname{Pax} 8$ mutations in a relatively large cohort of affected patients. A family history of thyroid dysgenesis was found in nine patients $(40 \%)$, whose affected relatives had ectopic thyroid $(n=4)$, athyreosis $(n=1)$, thyroid hemiagenesis $(n=2)$, or thyroglossal duct cysts $(n=2)$. Screening for $\operatorname{Pax} 8$ mutations identified abnormal migration profiles by SSCP analysis in 3 patients, but direct sequencing did not show coding region mutations in any of
\end{abstract}

\section{ABSTRACT}

the 22 patients. In conclusion, this study provides the first evidence that thyroid hemiagenesis can occur as a familial disorder associated with any form of thyroid dysgenesis. This finding supports both a common underlying mechanism to the various abnormalities in thyroid development and a role for genetic factors; however, our results from Pax 8 analysis suggest that this gene may not be a key factor. (Pediatr Res 57: 908-913, 2005)

TD, thyroid dysgenesis

THG, thyroid hemiagenesis
THG, a disorder in which one lobe of the gland fails to develop or regress, is believed to be the rarest of all thyroid gland developmental abnormalities. Thyroid gland embryogenesis starts during the fourth gestational week as an endodermal outpouching arising from the pharyngeal floor at the foramen cecum, penetrating within the surrounding mesoderm, and elongating into a bilobed diverticulum (1). This thyroid anlage descends into the neck, reaching its final position just inferior to the cricoid cartilage by wk 7 of gestation. During migration, the gland remains connected to the floor of the mouth by the thyroglossal duct, which usually later disappears. Hemiagenesis of the thyroid gland is a disturbance of the lobulation process that may result either from failure of the anlage to

Received July 13, 2004; accepted October 18, 2004.

Correspondence: Michel Polak, M.D. Ph.D., Paediatric Endocrinology Unit, INSERM EMI 0363, Necker Enfants-Malades Hospital, 149 rue de Sèvres, 75015 Paris, France; e-mail: michel.polak@nck.ap-hop-paris.fr

Supported by a grant from the Foundation for Medical Research (FRM) to M.C.

DOI: 10.1203/01.PDR.0000161409.04177.36 become bilobed and to spread out on both sides or from involution of one side of the bilobed structure.

Fewer than 100 cases were reported, most being incidental autopsy discoveries, as the mere absence of one lobe did not usually cause clinical symptoms. The accurate prevalence was not well established as thyroid function was usually normal (2-4). Recent routine thyroid ultrasound examinations estimated the prevalence between $0.05 \%$ and $0.2 \%(5,6)$.

The pathogenesis of unilateral thyroid agenesis is unknown. A hypothesis put forward in 1949 (7) incriminated congenital unilateral absence of the thyroid vasculature, but some patients with THG have been reported with normal vasculature. In contrast, vascular anomalies of the thyroid are reported in patients with normal bilobar glands. Therefore, these contradictory data cast a doubt on this mechanism (8). Recently, we reported family clustering of ectopic thyroid gland in association with hemithyroid, suggesting the involvement of underlying mechanisms, at least for these two forms of TD (9). Moreover, in previous studies, we found that familial forms of TD were significantly more common than can be attributed to 
chance alone, an observation that supports the involvement of genetic factors $(10,11)$.

Four genes involved in thyroid gland development have been identified to date: three encode thyroid-specific transcription factors (TTF-1 or Nkx2.1, TTF-2 or FOXE1, and Pax8) (12-19) and one encodes the TSH receptor gene (20-25). We recently performed a linkage analysis using these genes as candidate loci in several multiplex families with various forms of TD and found positive Pax8 linkage with identical genotypes in two brothers who had THG (unpublished data), suggesting a role for $\operatorname{Pax} 8$ in this abnormality. Such a role is consistent with a report in abstract form of a heterozygous Pax8 mutation in a familial case of THG (26) and with the finding of THG in pax8 and titfl double knock-out mice (27).

Taken together, these observations led us to postulate 1) that THG may be a familial disease and 2) that the $\operatorname{Pax} 8$ gene may be a candidate gene for THG. To investigate these hypotheses, we described the clinical characteristics and looked for Pax8 mutations in a cohort of patients affected by hemithyroid.

\section{PATIENTS AND METHODS}

Patients. Twenty-two patients with THG were studied retrospectively. All were unrelated individuals, except two brothers (Fig. 1). The patients were recruited either as part of our ongoing study of familial TD $(9,11)$ or on a voluntary basis by a network of pediatricians and other physicians known to be involved in the treatment of thyroid diseases. The diagnosis was made by thyroid ultrasonography and/or scintiscan $\left(99^{\mathrm{m}} \mathrm{Technetium}\right.$ or ${ }^{123}$ Iodine). Details on the mode of discovery, clinical manifestations, thyroid function, side of agenesis, presence or absence of isthmus, volume of the existing lobe, and extrathyroidal malformations or associated diseases were requested from the pediatricians managing the patients. We directed special attention to the presence of ureterovesical and renal malformations that could suggest involvement of the Pax8 gene. To estimate the volume of the existing thyroid lobe, we corrected for age-related thyroid gland volume differences using the table developed by Glaser and Styne (28). In addition, a careful detailed family history was obtained by the pediatricians following the patients.

This study was conducted with the agreement of the CCPPRB (Committee for Protection of Person involved in Biomedical Research), as requested by French law, and the participants or parents provided informed consent.

Single-stranded conformational polymorphism (SSCP). Genomic DNA was prepared from peripheral blood lymphocytes using a standardized method. The coding region covering the exons 1 to 11 and their intron/exon boundaries of the Pax8 gene was amplified by PCR in $20-\mu \mathrm{L}$ reactions using 11 primer pairs as described elsewhere (16). The PCR buffer contained $20 \mathrm{mM}$ Tris-HCl pH 8.0, $50 \mathrm{mM} \mathrm{KCl}, 1.5 \mathrm{mM} \mathrm{MgCl} 2,5$ or $10 \%$ DMSO, $160 \mu \mathrm{M}$ dNTPs, 0.4 pmoles ${ }^{33} \mathrm{P}$-dCTP $(2500 \mathrm{Ci} / \mathrm{mmol}), 0.25 \mathrm{U}$ AmpliTaq DNA polymerase (PerkinElmer Life Science, Boston, MA), 20 pmoles of each primer, and $100 \mathrm{ng}$ of genomic DNA. The PCR were performed using a GeneAmp 9700 thermal cycler (PerkinElmer) under previously described conditions (16). The PCR of the exons 1,10 , and 11 were performed using the following primers respectively: 5'-GCAGGCATCGAATCTCATC -3' and 5'-ACGCACGGACGCTCAG -3' primers for exon 1; 5'-TGATGCCCTTCACCTCAC -3'and 5'-ATCTGAGGACTCCCAGCTTT -3' primers for exon 10; 5'-GGTGCAATTTTCCTTTCTGA - 3 ' and 5'-TTCCTTTGTGTGACTCTCTGG -3' primers for exon 11.

The control group was composed of anonymous samples from 50 individuals without thyroid abnormalities. SSCP analysis was performed for exons 2 to 9 by diluting the PCR products 2 -fold in a buffer containing $98 \%$ formamide, $8 \mathrm{mM}$ EDTA, $0.1 \%$ bromophenol blue, and $0.1 \%$ xylene cyanol. This mixture was denatured at $95^{\circ} \mathrm{C}$ for $7 \mathrm{~min}$ and loaded onto a nondenaturing gel [25\% MDE gel solution (Tebu, Le Perray en Yvelines, France) 60\% TBE 1×]. The gels were run at room temperature and at $4{ }^{\circ} \mathrm{C}$, at $7 \mathrm{~W}$ constant power, for 13-15 h, then dried on the glass plate and exposed for 48-72 h on Kodak films (Biomax MR, Eastman Kodak, Rochester, NY).

Direct sequencing. When anomalous SSCP migration patterns were observed, genomic DNA was amplified using the same primer pairs as for SSCP (see above), and both forward and reverse strands were sequenced using the fluorometric method (DyeDeoxy Terminator Cycle Sequencing kit, Applied
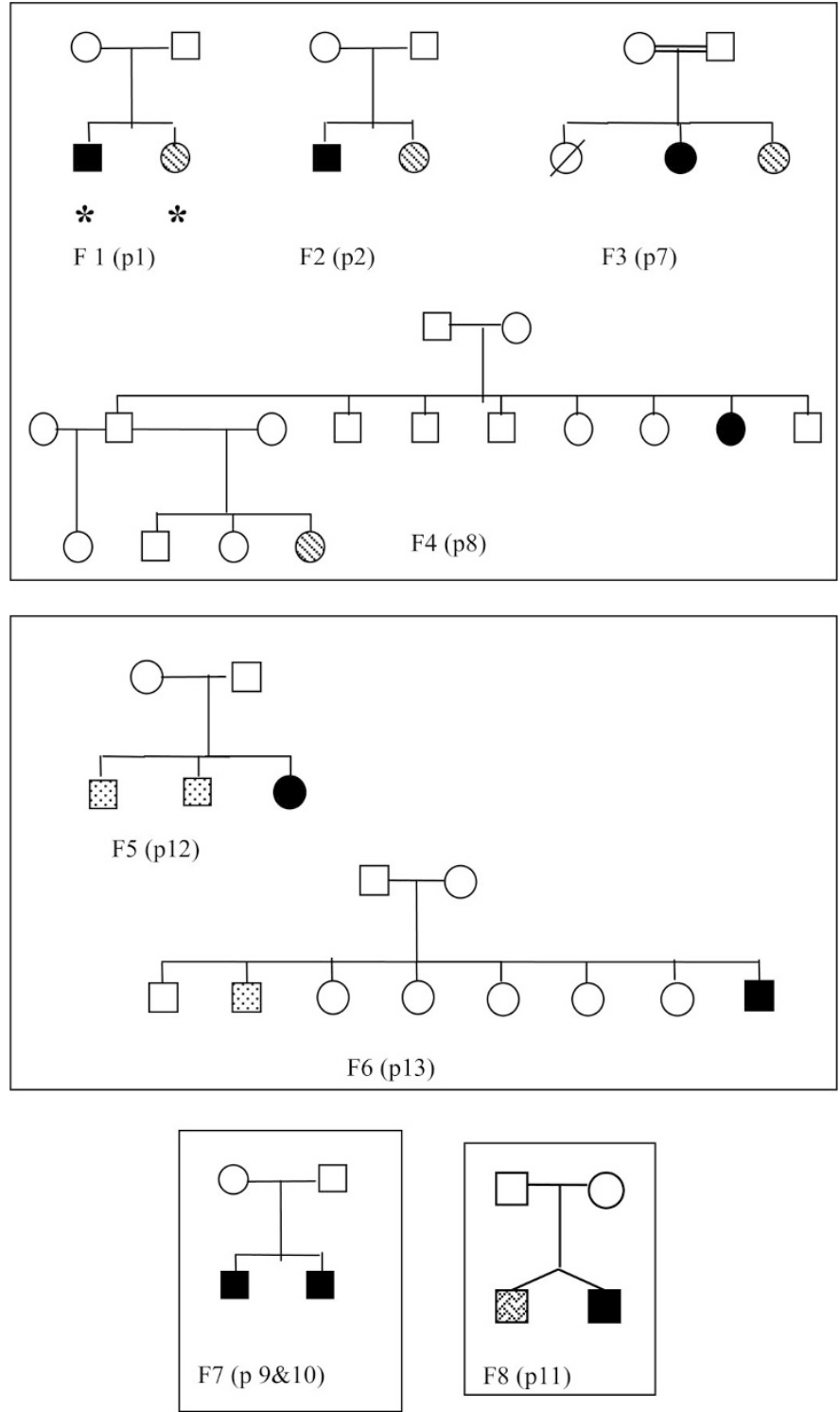

Figure 1. Familial forms of TD including hemithyroid. A history of TD in at least one relative was found in nine patients belonging to the eight multiplex families shown in this figure. In seven of these eight families, a single relative was known to have TD, whereas in the remaining family (F5), three firstdegree relatives were affected. Thyroid abnormalities in these families consisted of THG only $(n=1)$, THG with ectopy $(n=4)$, THG with athyreosis $(n=1)$, or THG with thyroglossal duct cysts $(n=2)$. The affected first-degree relatives were siblings in eight of these nine patients; in the remaining case, an aunt and her niece were affected. Ureterovesical malformations were found in only one family (number 1), in both members with TD. thyroid hemiagenesi, 圈 athyréosis, $\mathbb{Q}$ ectopic thyroid gland, 圆 thyroglossal duct cysts.

Biosystems, Foster City, CA). Furthermore, exons 1, 10, and 11 were directly sequenced after PCR amplification.

\section{RESULTS}

Clinical findings. The clinical profiles of the 22 study patients with THG are summarized in Table 1 . There were 14 females and 8 males (female/male ratio, 1.75).

Mode of discovery and thyroid function. In 13 of the 22 patients, THG was discovered either fortuitously by abnormal palpation $(n=7)$ or by cervical ultrasonography $(n=6)$. In three of the six cases, discovered by cervical ultra-sonography, 


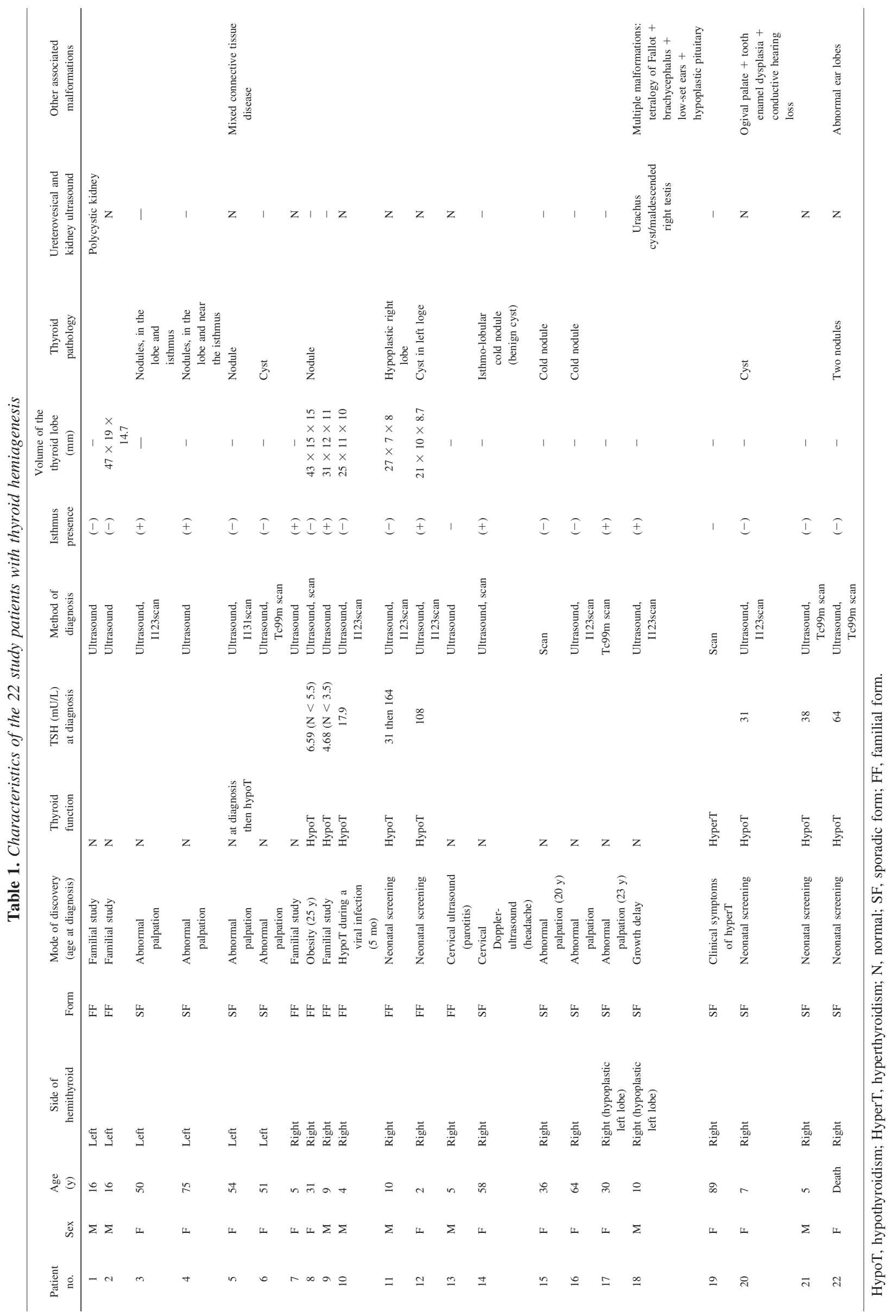


ultrasound was performed because of a family case of congenital hypothyroidism due to athyreosis or ectopic thyroid (9). In two other cases, neck ultrasound was performed to investigate parotitis $(n=1)$ or cervical vasculature because of headache ( $n$ $=1$ ). In one subject, the thyroid was investigated as part of an evaluation for growth delay. Thyroid function was normal in these 13 patients.

In one patient (number 9), THG was discovered fortuitously by cervical ultrasound performed because of a familial case of hemithyroid, and thyroid function testing showed asymptomatic hypothyroidism with mild TSH elevation.

In the eight other patients, THG was discovered upon evaluation for thyroid dysfunction, usually hypothyroidism ( $n=$ $7)$, although one patient had hyperthyroidism $(n=1)$ due to autonomous function of the existing thyroid lobe. Of the seven cases of hypothyroidism, five were detected by routine neonatal screening, one was diagnosed at 5 mo of age during a viral infection, and one was recognized during evaluation of obesity in adulthood.

Characteristics of the hemithyroid. The diagnosis of THG was established by ultrasonography and scintigraphy (using ${ }^{123}$ I or $\mathrm{Tc} 99 \mathrm{~m}$ ) in 13 patients, scintigraphy only in 3 patients, and ultrasonography only in 6 patients. The missing lobe was the left lobe in 16 patients and the right lobe in 6 patients (right over left hemithyroid ratio, 2.7). Two patients had severe hypoplasia of one lobe but were, nevertheless, kept in the study because severe hypoplasia of a lobe may be equivalent to hemithyroid (6). The isthmus was visualized in 8 (40\%) of 20 subjects; information on the isthmus was not available for 2 patients. The volume of the single lobe was determined in six patients and, after correction for age-related differences, it was found to be increased in three patients and normal in the other three patients. In the 16 remaining patients, lobe size data were not available.

Familial forms. A history of TD in at least one relative was found in $9(40 \%)$ of the 22 patients. These nine patients belong to the eight multiplex families shown in Figure 1. In seven of these eight families, a single relative was known to have TD, whereas in the remaining family (number 5 in Fig. 1), three first-degree relatives were affected. Thyroid abnormalities in these families consisted of THG only $(n=1)$, THG with ectopy $(n=4)$, THG with athyreosis $(n=1)$, or THG with thyroglossal duct cysts $(n=2)$. The affected first-degree relatives were siblings in eight of these nine patients; in the remaining case, an aunt and her niece were affected.

Extrathyroidal congenital malformations or disease. Investigations for extrathyroidal congenital malformations or disease were done in 12 patients and were positive in 5 (41.6\%). Two (16.6\%) patients had structural renal system abnormalities, either polycystic kidney with a family history of familial polycystic disease or a urachus cyst and maldescended right testis; this last patient also had cardiac (tetralogy of Fallot), neural (hypoplastic pituitary with GH deficiency), and auditory malformations (low-set ears) (normal karyotype). Two other patients had extrathyroidal malformations: one had facial abnormalities with an ogivale palate, tooth enamel dysplasia, and conductive hearing loss; and the other had ear lobe abnormal- ities. Finally, one patient had mixed connective tissue disease (Sharp syndrome).

SSCP and direct sequencing of the Pax8 gene. SSCP analysis was used as a first approach to identify mutations in patients with THG. In three patients, we found several abnormal bands in exon 6 of the Pax 8 gene, which were absent in the 50 normal controls studied (Fig. 2). However, direct sequencing failed to reveal sequence alterations in these three patients. In the seven other Pax8 exons studied, the migration patterns were normal. In the 3 exons that were directly sequenced, no mutations were found. Therefore, we concluded that none of the 22 patients had mutations in the coding region of the Pax 8 gene.

\section{DISCUSSION}

Congenital THG is thought to be an uncommon developmental abnormality. Several hypotheses involving embryogenetic abnormalities have been put forward to explain the absence of one thyroid lobe, but none has been confirmed to date. In theory, either environmental or genetic factors could explain the abnormality in the lobulation process. To gain insight into the pathogenesis of THG, we studied a series of 22 cases.

The diagnosis of THG was based upon ultrasonography in most patients, as ultrasound has been found clearly superior over scintigraphy for the diagnosis of THG (5). The missing lobe was usually the left one $(74 \%)$ and the isthmus was present in $40 \%$ of cases, in keeping with data from previous large series $(2,4,29)$. Why the left lobe is more often affected remains unexplained, but, interestingly, agenesis of paired organs is also more likely to occur on the left side $(2,30)$. Regarding the thyroid function, it was within the normal range in the majority of patients $(59 \%)$, which could suggest that a single thyroid lobe is capable of covering hormone requirements. However, in one patient with slightly elevated neonatal TSH, hypothyroidism was revealed during a viral infection at 5 mo of age, suggesting that the thyroid reserve may be insufficient to cover increased requirements. Although enlargement of the existing lobe has usually been described (6), no major compensatory enlargement was found in the present

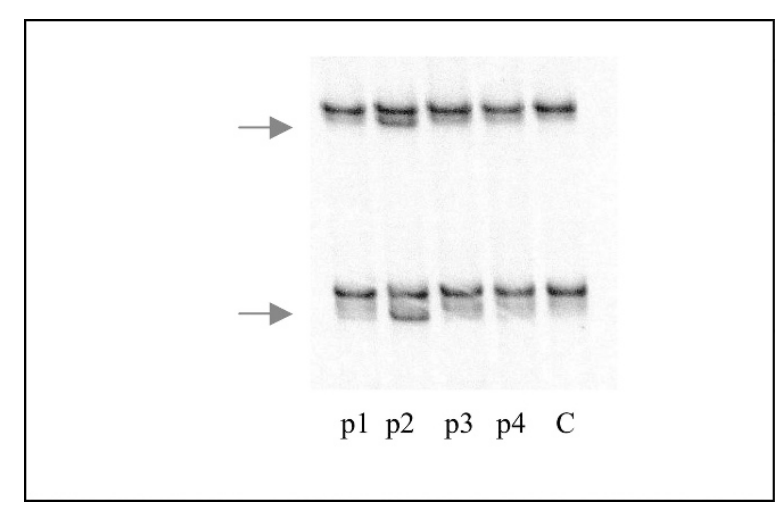

Figure 2. Abnormal profile of migration in SSCP in exon 6 of the Pax8 gene. SSCP showed two abnormal bands, shown by the arrows, in one patient affected by hemithyroid (p2) compared with three other patients studied affected by the same disease ( $1, \mathrm{p} 3$, and $\mathrm{p} 4)$ that showed the same profile as the control $(\mathrm{C})$. 
study in any of the six patients in whom this was investigated in accordance with the report of Shabana et al. (5). Among the patients with thyroid dysfunction, most had hypothyroidism (87.5\%). This was in accordance with the Mikosch et al. (29) but contrasts with earlier report that found $24 \%$ of THG patients with abnormal thyroid function, among whom only $2.8 \%$ with hypothyroidism (2). In the present study, the higher rate of hypothyroidism in the present series may be ascribable to recruitment bias, as some patients were from our previous studies of familial congenital hypothyroidism due to $\operatorname{TD}(9,11)$.

Although THG has usually been considered sporadic, a report of absence of the right lobe in two sisters strongly suggests a role for an inherited factor (31). In the present study, we found that 9 of the 22 patients, from eight families, had a family history of TD. Spectrum of clinical presentation occurred in a same family, with one member having hemithyroid and the other affected family members displaying either THG (in one family), ectopic thyroid (in four families), athyreosis (in one family), or thyroglossal duct cysts (in two families). Familial clustering of THG and ectopic thyroid has been previously reported, including affected monozygotic twin brothers $(9,32-34)$, which might suggest sharing pathogenic mechanisms between these two forms of TD. Congruent with this possibility was a report of one patient who had both THG and a small ectopic sublingual thyroid gland (35). In contrast, we are not aware of other reports of THG with athyreosis or thyroglossal duct cysts in the same family. In the report by Cassio et al. (36), THG was found in the euthyroid mother of a child with congenital hypothyroidism due to TD, but the type of TD was not specified. Likewise, THG associated with thyroglossal duct cyst, a minor developmental abnormality, has been reported in one patient (37), but our study seems to be the first to document the occurrence of one or the other of these two abnormalities in two relatives within the same family. Therefore, our study provides the first compelling evidence that THG can occur in combination with all types of TD, suggesting that ectopic thyroid, athyreosis, thyroglossal duct cysts, and THG may be variants of the same developmental abnormality. Although a role for humoral or environmental factors controlling the descent and development of the thyroid gland cannot be completely ruled out, these familial data argue in favor of genetically determined mechanisms.

In the past decade, molecular studies have identified four genes involved in thyroid development. The phenotype of the knock-out mice for each of these genes, particularly the complete absence of thyroid follicular cells (with normal C-cells) seen in pax8-1- mice (38), led us to suspect a role for Pax8 later in the course of thyroid development compared with TTF 1 or TTF2. In addition, one heterozygous Pax8 mutation was reported in abstract form in a familial case of THG (26) and THG was found in pax8 and titfl double knock-out mice (27). Taken together, although Pax8 mutations were generally found in patients affected by thyroid hypoplasia, these data allowed us to postulate that $\operatorname{Pax} 8$ might be a relevant candidate gene in THG. However, although SSCP analysis showed abnormal migration profiles, direct sequencing did not identify any Pax8 mutations, which may be explained by additional PCR products given by the Taq polymerase that altered DNA migration during SSCP. In the literature, only one patient with THG and Pax 8 mutation had ureterovesical-associated malformations (26), in keeping with experimental evidence that $\operatorname{Pax} 8$ is expressed in the developing thyroid and kidney (39). Thus, it could be that $\operatorname{Pax} 8$ mutations were found only in patients with multiple malformations. However, in the report by Krude et al. (26), the father affected by asymptomatic THG had the same Pax8 mutation as his affected son but had no ureterovesical malformations. In addition, $\operatorname{Pax} 8$ mutations have been reported in patients with thyroid gland hypoplasia but no structural abnormalities of the kidneys $(17,19)$. Thus, the absence of Pax8 mutations in the patients of our series cannot be ascribed to the absence of associated ureterovesical malformations and suggests that $\operatorname{Pax} 8$ may not play a key role in the pathophysiology of THG or of other forms of TD under the likely hypothesis of a common underlying mechanism. Nevertheless, screening for Pax8 mutations in populations with any form of TD found low mutation rates of $2-4 \%(16,19)$. In addition, mutations in the promoter of Pax8 that could lead to haploinsufficiency and therefore to hemithyroid phenotype were not searched for in our study. Thus, further studies are needed in larger populations to investigate the involvement of Pax8.

On the other hand, under the genetic hypothesis, as bilobation of the thyroid diverticulum occurs early during development, THG may be related to genes that are involved in the early stages of thyroid development, such as TTF1 or TTF2. However, mutations in these two genes have been identified so far only in patients with athyreosis or thyroid hypoplasia $(12,14,15)$. Therefore, these data suggest the involvement of other genes such as Sonic Hedgehog gene (shh), as recent genetic deletion caused THG in mice (40). Moreover, although we found a female predominance in our series of patients with THG, it was somewhat less marked (1.7:1) than in previous studies (3:1) (4). Additionally, in the subgroup with familial TD, males predominated 2 to 1 . Similarly, no female predominance was found in familial cases of athyreosis in our previous studies (11). These observations may suggest a potential role for sex-modified factors in the pathogenesis of total or partial agenesis of the thyroid gland, but further studies are needed to investigate this hypothesis.

Furthermore, although the family clustering in our series strongly supports a role for genetic factors, we did not obtain proof of an inherited basis for THG. Because we did not perform routine investigations in the patients' family members, we cannot estimate the rate of occurrence of familial THG. The high rate of familial clustering in the present study may be related to bias induced by the recruitment strategy used for this study $(9-11)$. Thus, further familial studies are needed to prove a role for genetic factors in THG.

In conclusion, the present study provides the first evidence that THG can occur as a familial disease in association with any form of TD. These data strongly suggest that ectopic thyroid, athyreosis, and THG may be variants of the same developmental abnormality. In addition, the familial clustering raises the possibility that the common underlying mechanisms may be, in part, genetically determined. Nevertheless, analysis of the candidate gene Pax8 in our cohort found no mutations, suggesting that Pax 8 may not be a key genetic factor in this disorder and that other genes may be involved. 
Acknowledgments. The authors thank the APDPHE for indefatigably supporting our work, T. Sanchis (Robert Debré Teaching Hospital, Paris) for maintaining the DNA bank, and the pediatricians who participated in this study, most notably P. Barat (Bordeaux), M. Houang (Paris), A. Léger (Paris), M. Nicolino and M. David (Lyon), M. Nivelon (Dijon), C. Raynaud-Ravni (St. Etienne), V. Sulmont and P.F. Souchon (Reims), and J. Weill (Lille).

\section{REFERENCES}

1. Larsen WJ 1993 Human Embryology: Development of the Head, the Neck, and the Eyes and Ears. Churchill Livingstone, New York, pp 335-337

2. Friedman A, Bauman A 1979 Hemiagenesis of the thyroid. Southern Med J 72:927929, 932

3. McHenry CR, Walfish PG, Rosen IB, Lawrence AM, Paloyan E 1995 Congenital thyroid hemiagenesis. Am Surg 61:634-639

4. Melnick JC, Stemkowski PE 1981 Thyroid hemiagenesis (hockey stick sign): a review of the world literature and a report of four cases. J Clin Endocrinol Metab 52:247-251

5. Shabana W, Delange F, Freson M, Osteaux M, De Schepper J 2000 Prevalence of thyroid hemiagenesis: ultrasound screening in normal children. Eur J Pediatr 159:456-458

6. Maiorana R, Carta A, Floriddia G, Leonardi D, Buscema M, Sava L, Calaciura F, Vigneri R 2003 Thyroid hemiagenesis: prevalence in normal children and effect on thyroid function. J Clin Endocrinol Metab 88:1534-1536

7. Garven-Thomas AC 1949 Hemiaplasia of thyroid gland. Med J Aust 2:97-98

8. Mariani G, Molea N, Toni MG, Bianchi R 1980 Thyroid hemiagenesis: a review of thirteen consecutive cases. J Nucl Med Allied Sci 24:183-187

9. Léger J, Marinovic D, Garel C, Bonaïti-Pellié C, Polak M, Czernichow P 2002 Thyroid developmental anomalies in first degree relatives of children with congenital hypothyroidism. J Clin Endocrinol Metab 87:575-580

10. Castanet M, Lyonnet S, Bonaïti-Pellié C, Polak M, Czernichow P, Léger J 2000 Familial forms of thyroid dysgenesis among infants with congenital hypothyroidism. N Engl J Med 343:441-442

11. Castanet M, Polak M, Bonaïti-Pellié C, Lyonnet S, Czernichow P, Léger J; On behalf of AFDPHE (Association Francaise pour le Depistage et la Prevention des Handicap de l'Enfant) 2001 Nineteen years of national screening for congenital hypothyroidism: familial cases with thyroid dysgenesis suggest the involvement of genetic factors. J Clin Endocrinol Metab 86:2009-2014

12. Krude H, Schuetz B, Biebermann H, von Moers A, Schnabel D, Neitzel H, Tönnies H, Weise D, Lafferty A, Schwarz S, DeFelice M, von Deimling A, van Landeghem F, DiLauro R, Grüters A 2002 Choreoathetosis, hypothyroidism, and pulmonary alterations due to human NKX2-1 haploinsufficiency. J Clin Invest 109:475-480

13. Pohlenz J, Dumitrescu A, Zundel D, Martiné U, Schönberger W, Koo E, Weiss RE, Cohen RN, Kimura S, Refetoff S 2002 Partial deficiency of thyroid transcription factor 1 produces predominantly neurological defects in humans and mice. J Clin Invest 109:469-473

14. Clifton-Bligh RJ, Wentworth JM, Heinz P, Crisp MS, John R, Lazarus JH, Ludgate M, Chatterjee VK 1998 Mutation of the gene encoding human TTF-2 associated with thyroid agenesis, cleft palate and choanal atresia. Nat Genet 19:399-401

15. Castanet M, Park SM, Smith A, Bost M, Léger J, Lyonnet S, Pelet A, Czernichow P, Chatterjee K, Polak M 2002 A novel loss-of-function mutation in TTF-2 is associated with congenital hypothyroidism, thyroid agenesis, and cleft palate. Hum Mol Genet 11:2051-2059

16. Macchia PE, Lapi P, Krude H, Pirro MT, Missero C, Chiovato L, Souabni A, Baserga M, Tassi V, Pinchera A, Fenzi G, Grüters A, Busslinger M, Di Lauro R 1998 PAX mutations associated with congenital hypothyroidism caused by thyroid dysgenesis. Nat Genet 19:83-86

17. Congdon T, Nguyen LQ, Nogueira CR, Habiby RL, Medeiros-Neto G, Kopp P 2001 A novel mutation (Q40P) in PAX8 associated with congenital hypothyroidism and thyroid hypoplasia: evidence for phenotypic variability in mother and child. J Clin Endocrinol Metab 86:3962-3967

18. Komatsu M, Takahashi T, Takahashi I, Nakamura M, Takahashi I, Takada G 2001 Thyroid dysgenesis caused by PAX8 mutation: the hypermutability with $\mathrm{CpG}$ dinucleotides at codon 31. J Pediatr 139:597-599

19. Vilain C, Rydlewski C, Duprez L, Heinrichs C, Abramowicz M, Malvaux P, Renneboog B, Parma J, Costagliola S, Vassart G 2001 Autosomal dominant transmission of congenital thyroid hypoplasia due to loss-of-function mutation of PAX8. J Clin Endocrinol Metab 86:234-238

20. Abramowicz MJ, Duprez L, Parma J, Vassart G, Heinrichs C 1997 Familial congenital hypothyroidism due to inactivating mutation of the thyrotropin receptor causing profound hypoplasia of the thyroid gland. J Clin Invest 99:3018-3024

21. Biebermann H, Schöneberg T, Krude H, Schultz G, Gudermann T, Grüters A 1997 Mutations of the human thyrotropin receptor gene causing thyroid hypoplasia and persistent congenital hypothyroidism. J Clin Endocrinol Metab 82:3471-3480

22. Gagne N, Parma J, Deal C, Vassart G, Van Vliet G 1998 Apparent congenital athyreosis contrasting with normal plasma thyroglobulin levels and associated with inactivating mutations in the thyrotropin receptor gene: are athyreosis and ectopic thyroid distinct entities? J Clin Endocrinol Metab 83:1771-1775

23. Tiosano D, Pannain S, Vassart G, Parma J, Gershoni-Baruch R, Mandel H, Lotan R, Zaharan Y, Pery M, Weiss RE, Refetoff S, Hochberg Z 1999 The hypothyroidism in an inbred kindred with congenital thyroid hormone and glucocorticoid deficiency is due to a mutation producing a truncated thyrotropin receptor. Thyroid 9:887-894

24. Tonacchera M, Agretti P, Pinchera A, Rosellini V, Perri A, Collecchi P, Vitti P, Chiovato L 2000 Congenital hypothyroidism with impaired thyroid response to thyrotropin (TSH) and absent circulating thyroglobulin: evidence for a new inactivating mutation of the TSH receptor gene. J Clin Endocrinol Metab 85:1001-1008

25. Bretones P, Duprez L, Parma J, David M, Vassart G, Rodien P 2002 A familial case of congenital hypothyroidism caused by a homozygous mutation of the thyrotropin receptor gene. Thyroid 11:977-980

26. Krude H, Macchia PE, Di Lauro R, Grüters A 1998 Familial hypothyroidism due to thyroid dysgenesis caused by dominant mutations of the Pax 8 mutations gene. Horm Res 50:045

27. De Felice M, Di Lauro R 2004 Thyroid development and its disorders: genetics and molecular mechanisms. Endocr Rev 25:722-746

28. Glaser NS, Styne DM 1997 Predictors of early remission of hyperthyroidism in children. J Clin Endocrinol Metab 82:1719-1726

29. Mikosch P, Gallowitsch HJ, Kresnik E, Molnar M, Gomez I, Lind P 1999 Thyroid hemiagenesis is an endemic goiter area diagnosed by ultrasonography: report of sixteen patients. Thyroid 9:1075-1084

30. Shaha AR, Gujarati R 1997 Thyroid hemiagenesis. J Surg Oncol 65:137-140

31. Rajmil HO, Rodriguez-Espinosa J, Soldevila J, Ordonez-Llanos J 1984 Thyroid hemiagenesis in two sisters. J Endocrinol Invest 7:393-394

32. Rosenberg T, Gilboa Y 1980 Familial thyroid ectopy and hemiagenesis. Arch Dis Child 55:639-641

33. Orti E, Castells S, Qazi QH, Inamdar S 1971 Familial thyroid disease: lingual thyroid in two siblings and hypoplasia of a thyroid lobe in a third. J Pediatr 78:675-677

34. McLean R, Howard N, Murray IP 1985 Thyroid dysgenesis in monozygotic twins: variants identified by scintigraphy. Eur J Nucl Med 10:346-348

35. Hsu CY, Wang SJ 1994 Thyroid hemiagenesis accompanying an ectopic sublingual thyroid. Clin Nucl Med 19:546

36. Cassio A, Cacciari E, Bal M, Colli C, Bellanova B 1997 Thyroid morphological findings in the mothers of infants with congenital hypothyroidism. Arch Dis Child $77: 185$

37. Tsang SK, Maher J 1998 Thyroid hemiagenesis accompanying a thyroglossal duct cyst: a case report. Clin Nucl Med 23:229-232

38. Mansouri A, Chowdhury K, Gruss P 1998 Follicular cells of the thyroid gland require Pax8 gene function. Nat Genet 19:87-90

39. Plachov D, Chowdhury K, Walther C, Simon D, Guenet JL, Gruss P 1990 Pax8, a murine paired box gene expressed in the developing excretory system and thyroid gland. Development 110:643-651

40. Fagman H, Grände M, Gritli-Linde A, Nilsson M 2004 Genetic deletion of Sonic hedgehog causes hemiagenesis and ectopic development of the thyroid in mouse. Am J Pathol 164:1865-1872 